\title{
Electrospray Ionization (ESI) Tandem Mass Spectrometric Analysis of meso-Tetrakis(Heptafluoropropyl)Porphyrin
}

\author{
Kimberly S. F. Lau, Martin Sadilek, Gamal E. Khalil, \\ and Martin Gouterman* \\ Department of Chemistry, University of Washington, Seattle, Washington \\ Christian Brückner \\ Department of Chemistry, University of Connecticut, Storrs, Connecticut, USA
}

The results of an electrospray ionization (ESI $(+)$ and ESI $(-))$ collision-induced fragmentation investigation of meso-tetrakis(heptafluoropropyl)porphyrin $\left(\mathbf{T}^{\mathrm{F}} \mathbf{H P}\right)$ are reported. The fragmentation patterns of $\mathbf{T}^{\mathrm{F}} \mathbf{H P}$ show, in both ionization modes, the formation of fragments with direct covalent meso-alkyl-to- $\beta$-linkages on elimination of HF. In addition, in the ESI $(+)$ mode, the losses of perfluoroalkyl radicals are observed. A detailed analysis of the fragmentation patterns allows conclusions to be drawn on the identification of the fragment species. Comparable cyclized products were previously produced using radical-initiated solutionphase syntheses. The results presented will help to analyze meso-perfluoroalkyl-derivatized porphyrinic macrocycles that are becoming increasingly popular. (J Am Soc Mass Spectrom 2005, 16, 1915-1920) (c) 2005 American Society for Mass Spectrometry

$\mathrm{M}$ eso-Tetraarylporphyrins, the parent compound of which is meso-tetrakisphenylporphyrin, are the most widely studied class of synthetic porphyrins [1]. Much less investigated are the corresponding meso-tetrakis-alkylporphyrins and mesoperfluoroalkylporphyrins [2-5]. In particular, the mesoperfluoroalkylporphyrins have proved useful in, for example, the design of synthetic monooxygenase mimicks [6]. In addition, their potential in both photodynamic therapy and in the in vivo imaging by fluorescence and ${ }_{19} \mathrm{~F}$ NMR (nuclear magnetic resonance) spectroscopy was evaluated [7].

Recently, the groups of Guo and Chen described, inter alia, the functionalization of meso-arylporphyrins with meso-fluoroiodo-alkanes (1) or fluorochloro-alkanes (2). Radical-induced deiodination or debromination resulted in the formation of terminal radicals that efficiently ring-closed with the neighboring $\beta$-positions to form products 3 and 4 , respectively (Scheme 1) $[8,9]$. Thus, a range of fused ring products enclosing five- and six-membered rings were prepared. These findings

Published online October 24, 2005

Address reprint requests to G. E. Khalil, Department of Chemistry, University of Washington, Box 351700, Seattle, WA 98195-1700, USA. E-mail: gkhalil@u.washington.edu or C. Brückner, Department of Chemistry, University of Connecticut, Unit 3060, Storrs, CT 06269-3060, USA. Also E-mail c.bruckner@uconn.edu.

* E-mail: goutermn@gibbs.chem.washington.edu

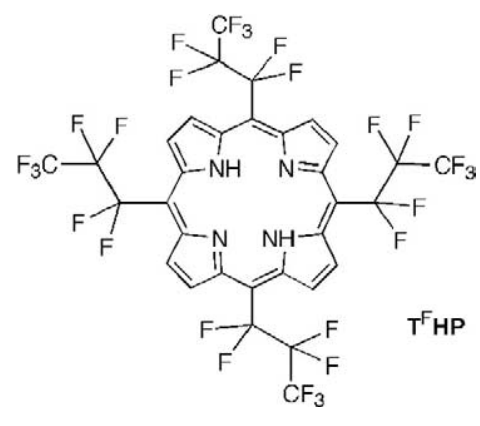

Structure 1

prompted the question whether meso-perfluoroalkylporphyrins such as meso-tetrakis(heptafluoropropyl)porphyrin $\left(\mathrm{T}^{\mathrm{F}} \mathbf{H P}\right)$ also undergo similar cyclizations. This study will answer this question affirmatively.

Here, we report the analysis of $\mathbf{T}^{\mathrm{F}} \mathbf{H P}$ by tandem electrospray ionization (ESI) mass spectrometry in the positive and negative mode. Using collision-induced fragmentation techniques, we find that rich fragmentation patterns in positive and negative ionization modes are observed. Next to the expected losses of radical fragments, HF eliminations are observed, which we attribute to the formation of polycyclic systems containing meso-alkyl-to- $\beta$-fusions. A detailed analysis of the spectra allows some conclusions to be drawn as to the nature of these products. 


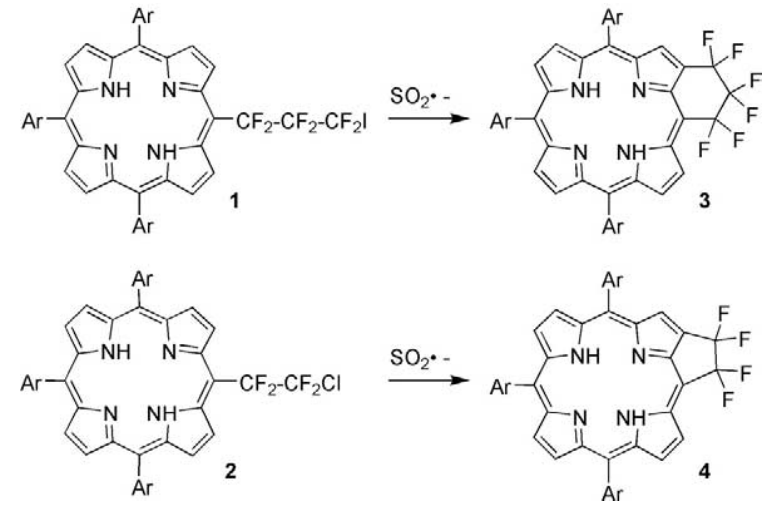

Scheme 1.

\section{Experimental Section}

$\mathrm{T}^{\mathrm{F}} \mathrm{HP}$ was purchased from Frontier Science, Inc., Logan, UT, USA. All mass spectrometry data were obtained using an EsquireLC ion trap mass spectrometer (Bruker Daltonics, Billerica, MA, USA) with an ESI source. Samples were dissolved in spectral grade $\mathrm{CH}_{2} \mathrm{Cl}_{2}$ and diluted in $\mathrm{CH}_{3} \mathrm{CN}$ to $10^{-4} \mathrm{M}$ concentrations. This solution was directly infused into the ion source at a flow rate of $1 \mu \mathrm{L} / \mathrm{min}$. Spectra were collected in both positive and negative ionization modes. The standard tune parameters were similar for both modes: capillary voltage, 3500-4000 V; $\Delta$ end plate, $500 \mathrm{~V}$; capillary offset, 70 $\mathrm{V}$; skimmer 1 set at $30 \mathrm{~V}$; skimmer 2 set at $4 \mathrm{~V}$; octupole, $3 \mathrm{~V}$ with $\Delta 2 \mathrm{~V}$, trap drive, $55-75 \mathrm{~V}$; ion charge control on and target, 25,000 (10,000 in negative mode for better isotope resolution); nebulizer gas $\left(\mathrm{N}_{2}\right), 12 \mathrm{psi}$; drying gas $\left(\mathrm{N}_{2}\right), 5 \mathrm{~L} / \mathrm{min}$; drying temperature, $250{ }^{\circ} \mathrm{C}$. The fragmentation spectra of the analytes were collected with an isolation width of 4 atomic mass units $(\mathrm{amu})$, fragmentation amplitude set to $1 \mathrm{~V}$, and SmartFrag on (amplitude automatically varies to $30-200 \%$ of the set fragmentation amplitude of $1 \mathrm{~V})$. The accuracy of the data is $\pm 0.3 \mathrm{amu}$.

\section{Results and Discussion}

ESI mass spectrometry is becoming a popular technique for the analyses of porphyrins and metalloporphyrins [10-16]. Free base porphyrins are readily protonated [14, 16]. Thus, ESI(+) is commonly used for the analysis of porphyrins and proves also to be suitable for the analysis of $\mathbf{T}^{\mathrm{F}} \mathbf{H P}$ (see the following section). For the simplicity and clarity of the resulting spectra and their interpretation, we will, however, first discuss our findings using the ESI in the negative ion detection mode (ESI(-)).

\section{Single and Tandem ESI(-) Mass Spectrometry Spectra of $\mathbf{T}^{\mathrm{F}} \mathbf{H} \mathbf{P}$}

The ESI(-) spectrum of $\mathbf{T}^{\mathrm{F}} \mathbf{H P}\left(\mathrm{C}_{32} \mathrm{H}_{10} \mathrm{~F}_{28} \mathrm{~N}_{4}\right.$, exact mass: $982.0458 \mathrm{amu})$, recorded in the negative ion mode, shows as the major species one peak at $\mathrm{m} / \mathrm{z}$ 981.3, corresponding to the species $\left[\mathrm{T}^{\mathrm{F}} \mathbf{H P}-\mathrm{H}\right]^{-}$. Ionization is thus brought about by deprotonation, presumably of one of the inner pyrrole-type nitrogens. The electronwithdrawing meso-perfluoroalkyl substituents increase the acidity of the porphyrin and make deprotonation possible. As expected for the soft ESI method, no fragment ions are observed [17].

Figure 1 shows the collision-induced fragmentation spectrum of the species at $\mathrm{m} / \mathrm{z} 981$. As the sole fragmentation pattern, the successive loss of six equivalents of HF (20 amu) is observed. Because a ciselimination of HF (hydrogen fluoride) cannot take place in $\mathbf{T}^{\mathbf{F}} \mathbf{H P}$, we surmise that the elimination is, under concomitant formation of a single bond, due to the loss of one $\mathrm{H}$ from the pyrrolic $\beta$-positions and the loss of one $\mathrm{F}$ from a flanking perfluoroalkyl group (Scheme 2). It can not be conclusively derived whether this reaction is due to a nucleophilic attack of a $\beta$-carbon at the fluoroalkyl chain or due to a radical-mediated process, but the absence of any radical fragmentations (cf. below to the corresponding fragmentation spectrum in the $\mathrm{ESI}(+)$ mode) suggests a substitution mechanism. This mechanism is also assisted by the negatively charged porphyrinic macrocycle. We, and others, have observed the formation of such linkages under mass spectrometry conditions in meso-perfluoroaryl-substituted porphyrins $[16,18]$.

The structure of the species at $\mathrm{m} / \mathrm{z} 961$ resulting from one loss of HF from $\left[\mathrm{T}^{\mathrm{F}} \mathbf{H P}-\mathrm{H}\right]^{-}$could be species $\mathbf{5 a}$, enclosing a six-membered ring, or $\mathbf{5} \mathbf{b}$, enclosing a fivemembered ring. The ESI(-) spectrum does not provide any indications of which species is formed. However, as we will show later, the ESI(+) spectrum provides clues that preferentially the six-membered ring is formed. Hence, the consecutive fragmentation products are formulated in Scheme $\mathbf{2}$ as the fused six-membered ring species. The second and subsequent two HF losses can result in the formation of numerous isomers. We surmise that the cyclizations occur in an unidirectional orientation. Instead of forming products such as $\mathbf{6 b}$, in which the two alkyl chains are linked to the same pyrrolic building block, isomer $\mathbf{6 a}$ is formed, in which the two alkyl chains are linked to two different pyrrolic units. We base this on a

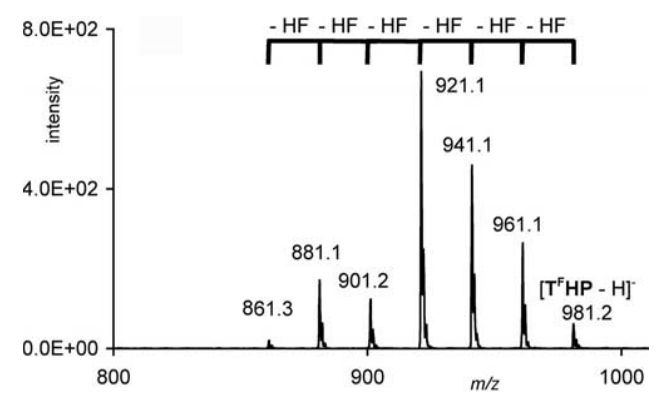

Figure 1. Collision-induced fragmentation spectrum of the species $\left[\mathbf{T}^{\mathbf{F}} \mathbf{H P}-\mathbf{H}\right]^{-}(\mathrm{m} / \mathrm{z}$ 981). An interpretation of the spectra is presented in Scheme 2. 

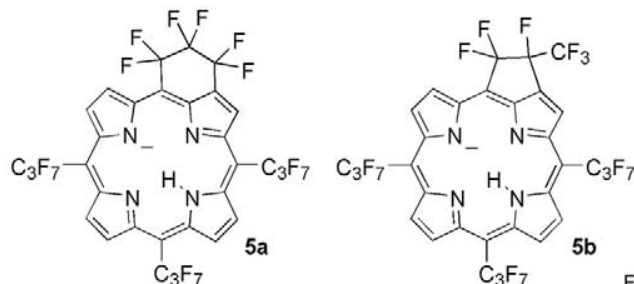

$\mathrm{C}_{32} \mathrm{H}_{8} \mathrm{~F}_{27} \mathrm{~N}_{4}$, 961.0
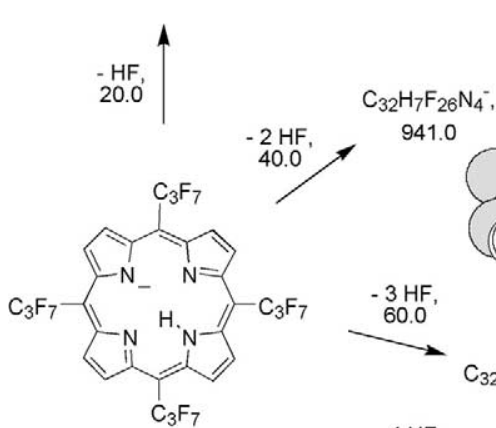

$\mathrm{C}_{3} \mathrm{~F}_{7}$

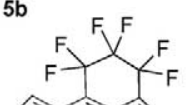
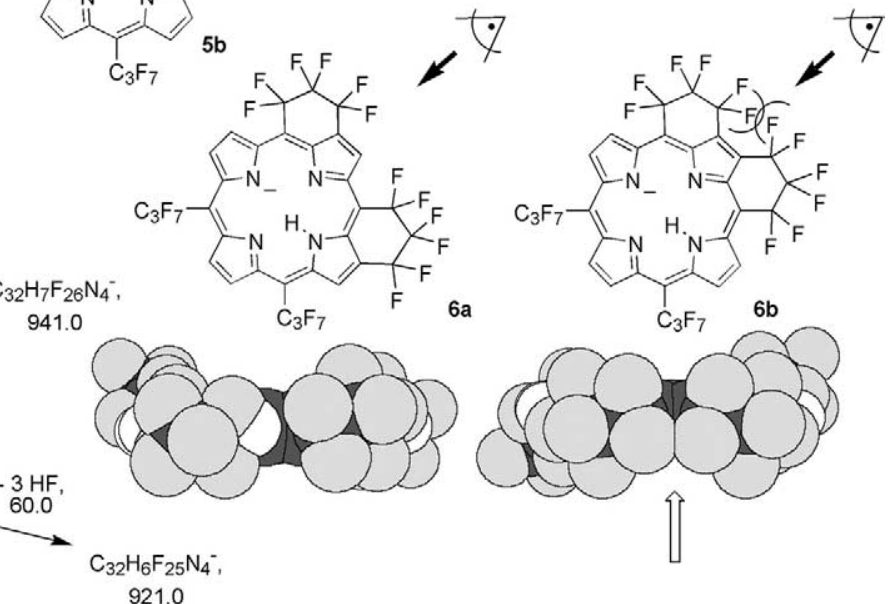

$\left[\mathrm{F}_{\mathrm{HP}}-\mathrm{H}\right.$

$\mathrm{C}_{32} \mathrm{H}_{9} \mathrm{~F}_{28} \mathrm{~N}_{4}^{-}, 981.0$

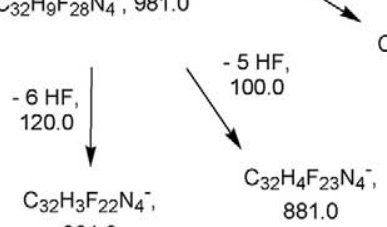
861.0

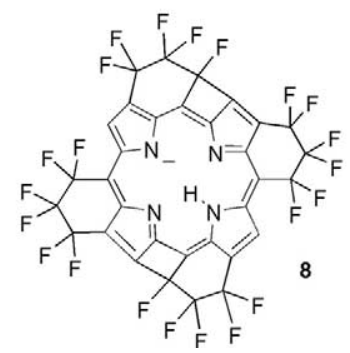

$-4 \mathrm{HF}$,

921.0

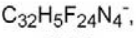

901.0

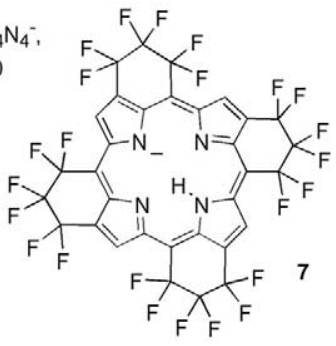

Scheme 2. Interpretation of the collision-induced fragmentation spectrum of $\left[\mathbf{T}^{\mathbf{F}} \mathbf{H P}-\mathrm{H}\right]^{-}$(Figure 1) Open arrow indicates steric interactions; the solid arrows indicate the view direction of the molecular model of 6a/b (energy-minimized, MM2 level, CS Chem 3D Pro, v. 5.0), shown in space-filling representation, atoms at $100 \%$ van der Waals radii, black: carbon, grey: fluorine, and white: hydrogen.

molecular modeling study (CS Chem 3D Pro, MM2 basis set). A space-filling representation of the energyminimized isomers $\mathbf{6 a}$ and $\mathbf{6 b}$ was generated and is shown in Scheme 2. Although isomer 6a is not sterically encumbered, significant overlap of the van der Waals radii of two fluorine atoms is clearly present in isomer $\mathbf{6 b}$. Hence, accounting for the cooperative interaction between the linkages, we have formulated the species 7 that resulted from the loss of four equivalents of HF as the symmetrically linked isomer.

The fifth and sixth loss of HF implies the formation of two more linkages, presumably forming fused fourmembered rings, as shown for $\mathbf{8}$. The position of the four-membered rings was, as shown, positioned to be opposite to each other but there is no experimental evidence to exclude the formation of these fusions in pyrrolic subunits adjacent to each other. Molecular modeling studies have revealed the metric possibility of these linkages although the porphyrin assumes a slightly domed conformation. This high-energy deformation is likely the reason the intensity of the ion peaks corresponding to the fifth and especially the sixth HF loss are small. No further fragmentations are observed in the tandem ESI(-) spectrum of $\left[\mathrm{T}^{\mathrm{F}} \mathbf{H P}-\mathrm{H}\right]^{-}$.

\section{Single and Tandem ESI(+) Mass Spectrometry Spectra of $\mathbf{T}^{\mathrm{F}} \mathbf{H P}$}

The single ESI mass spectrum of $\mathbf{T}^{\mathrm{F}} \mathbf{H P}$, recorded in the positive ion mode, shows one predominant species at $\mathrm{m} / \mathrm{z} 983.4$ that corresponds to the expected monoproto- 


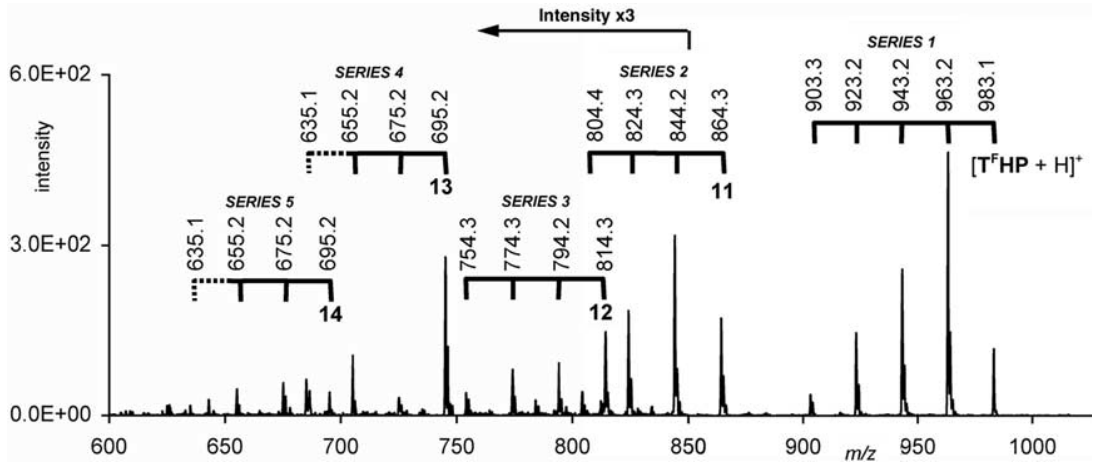

Figure 2. Collision-induced fragmentation spectrum of the species $\left[\mathbf{T}^{\mathbf{F}} \mathbf{H P}+\mathbf{H}\right]^{+}(\mathrm{m} / \mathrm{z} 983.1)$. Interpretation of the spectra and species designation in Scheme 3.

nated species [ $\left.\mathrm{T}^{\mathrm{F}} \mathrm{HP}+\mathrm{H}\right]^{+}\left(\mathrm{C}_{32} \mathrm{H}_{11} \mathrm{~F}_{28} \mathrm{~N}_{4}+\right.$, exact mass: 983.0531). The collision-induced fragmentation ESI $(+)$ spectrum of the species $\left[\mathrm{T}^{\mathrm{F}} \mathbf{H P}+\mathrm{H}\right]^{+}$(Figure 2) shows, in principal, similar HF-loss patterns as the ESI(-) spectrum, which we interpret in a similar fashion (Scheme 3). However, the spectrum is complicated by the fact that radical fragmentations are observed and that the fragments each undergo HF loss-mediated cyclization reactions.

The heaviest fragment is species 9 of $\mathrm{m} / \mathrm{z}$ 963, derived from $\left[\mathrm{T}^{\mathrm{F}} \mathrm{HP}+\mathrm{H}\right]^{+}$by loss of HF. Analogous to the negative ion mode spectrum, two possible structures can be formulated for this product, $\mathbf{9 a}$ and $\mathbf{9 b}$. The six-membered product $\mathbf{9 a}$ is set up for three more equivalent losses of $\mathrm{HF}$, all of which are observed, ultimately forming species 15 . The five-membered ring species $\mathbf{9 b}$ is not a likely structure for the ion of $m / z 963$. This is because the ESI(+) spectrum is characterized by the occurrence of many radical fragmentations of the heptafluoropropyl substituents (see in the following paragraph). This should make the formation of the highly stabilized radical $\mathbf{1 0}$ through loss of a $\mathrm{CF}_{3}$ radical likely. That fragment, however, is not observed. The mechanism for the cyclization reactions are, because of the observation of extensive radical fragmentations, of radical nature, although the very electron-rich nature of even a monoprotonated porphyrin ring may still allow nucleophilic substitution reactions to take place.

The tandem $\mathrm{ESI}(+)$ spectrum of $\left[\mathrm{T}^{\mathrm{F}} \mathbf{H P}+\mathrm{H}\right]^{+}$is, in contrast to its ESI(-) spectrum, rich of fragmentations of the heptafluoropropyl substituents. This circumstance provides valuable indications for the structure of the products. The spectrum allows the identification of five independent series of peaks, which are all derived from the parent ion $\left[\mathrm{T}^{\mathrm{F}} \mathrm{HP}+\mathrm{H}\right]^{+}$by different radical fragmentations of the heptafluoropropyl group(s): Series 1 through 5 , origination in the species $\mathbf{1 1}, \mathbf{1 2}, \mathbf{1 3}$, and $\mathbf{1 4}$, respectively. Each peak series is related through sequential losses of up to four molecules of HF (Figure 2B). All expected radical fragments from $\left[\mathrm{T}^{\mathrm{F}} \mathrm{HP}+\mathrm{H}^{+}\right.$are found: loss of $\mathrm{C}_{2} \mathrm{~F}_{5}$. from $\left[\mathbf{T}^{\mathrm{F}} \mathrm{HP}+\mathrm{H}\right]^{+}$leads to the formation of the stable benzylic radical species 11. Loss of one entire meso-group $\left(\mathrm{C}_{3} \mathrm{~F}_{7}\right)$ from $\left[\mathrm{T}^{\mathrm{F}} \mathrm{HP}+\mathrm{H}\right]^{+}$(or loss of $\mathrm{CF}_{2}$ from 11) generates the aromatic radical species 12. Further loss of a $\mathrm{CF}_{3}$. radical from 12 forms 13b. Alternatively, the diradical isomeric structure $13 b$, resulting from two sequential losses of $\mathrm{C}_{2} \mathrm{~F}_{5}$. from $\left[\mathbf{T}^{\mathrm{F}} \mathbf{H P}+\mathrm{H}\right]^{+}$, is also a likely structure for the species of $m / z 745$. The final alkyl-fragmentation product that can be traced is species $\mathbf{1 4}$ for which multiple origins can be assumed.

Fragment $\mathbf{1 1}$ undergoes all three expected HF losses with concomitant formation of six-membered rings. Once again, no product resulting from the loss of a $\mathrm{CF}_{3}$. from $\mathbf{1 1}$ or any of its HF condensation products are detected, supporting the benzylic radical structure $\mathbf{1 6}$ containing fused six-membered rings as the structure for the final product. For the same steric arguments provided previously, we show the symmetric condensation products derived from unidirectional ring fusions. An analogous analysis can be made for 12, leading to porphyrin radical 17.

An analysis of the fragmentation of species $\mathbf{1 3}$ does not allow its identification as either 13a or $\mathbf{1 3 b}$ because both structures are set up to undergo the observed two HF-mediated six-membered ring closures to form the two isomers of $\mathbf{1 8}$ shown. Finally, fragment $\mathbf{1 4}$ can undergo two subsequent HF extrusions, forming 19. In addition, HF losses from fragments 18 and 19 are observed, suggestive of the formation of four-membered rings (cf. to Scheme 2). This, and whether 18 and 19 undergo internal radical recombination processes, however, remains speculative.

\section{Conclusions}

We have shown the detailed mass spectrometric analysis of a meso-perfluoroalkylporphyrin. The overriding pattern observed in the positive and negative ion mode spectra are a series of HF eliminations we attribute to the formation of meso-alkyl-to- $\beta$-position fusion products. We are not aware of any reports describing this fragmentation pattern for meso-perfluoroalkylporphyrins. The results will facilitate the interpretation of mass spectrometry spectra of meso-perfluoroalkyl-substituted porphyrinic compounds using ESI mass spectrometry. The findings provide an understanding of the behavior 


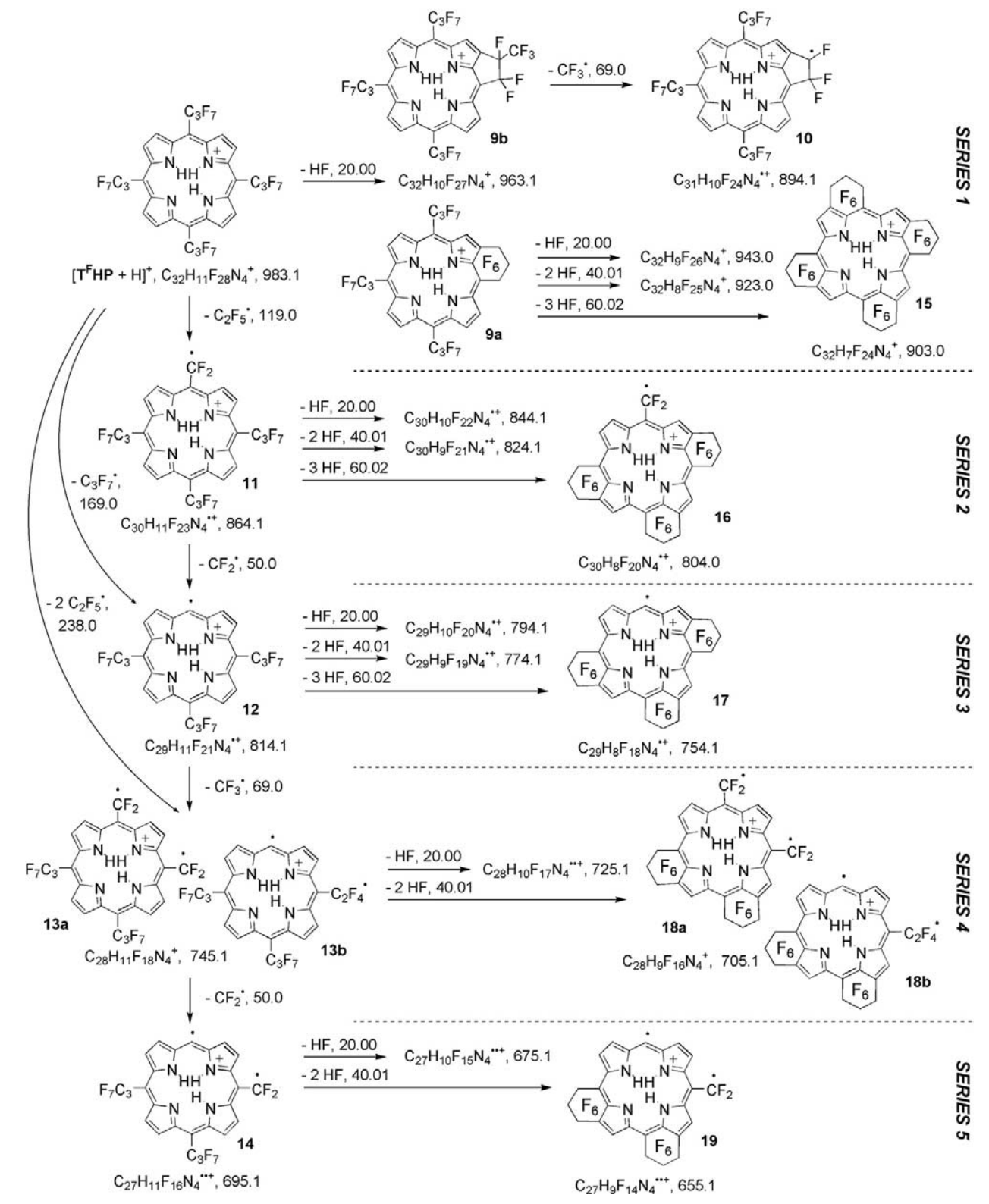

Scheme 3. Interpretation of the collision-induced fragmentation spectrum of $\left[\mathrm{T}^{\mathrm{F}} \mathbf{H P}+\mathrm{H}\right]^{+}$(Figure 2).

of fluoro-substituted meso-alkylporphyrins under ESI mass spectrometry conditions. Whether the observed fragmentation modes also can be adopted for the solution-phase bulk synthesis of porphyrins containing fused perfluorinated ring systems is currently a subject of investigations in our laboratories.

\section{Acknowledgments}

This work was supported by the Department of Defense MultiDisciplinary University Research Initiative (MURI) Center on Polymeric Smart Skin Materials through the Air Force Office of Scientific Research contract F49620-01-1-0364. The EsquireLC mass spectrometer was purchased with support by National Science Foundation under Grant 9807748.

\section{References}

1. Lindsey, J. S. In The Porphyrin Handbook; Guilard, R., Ed.; Academic Press: San Diego, 2000; Vol. 1, pp 45-118.

2. DiMagno, S. G.; Williams, R. A.; Therien, M. J. Facile Synthesis of meso-Tetrakis(perfluoroalkyl)porphyrins. J. Org. Chem. 1994, 59, 6943-6948.

3. DiMagno, S. G.; Wertsching, A. K.; Ross, I. I., C. R. Electronic Consequences of Nonplanar Core Conformations in ElectronDeficient Porphyrins: The Structure and Spectroscopic Properties of $[5,10,15,20-$ Tetrakis(heptafluoropropyl)porphinato $]$ cobalt(II). J. Am. Chem. Soc. 1995, 117, 8279-8280.

4. Goll, J. G.; Moore, K. T.; Ghosh, A.; Therien, M. J. Synthesis, Structure, Electronic Spectroscopy, Photophysics, Electrochemistry, and X-Ray Photoelectron Spectroscopy of HighlyElectron-Deficient $[5,10,15,20$-Tetrakis(perfluoroalkyl)porphi- 
natolzinc(II) Complexes and their Free Base Derivatives. J. Am. Chem. Soc. 1996, 118, 8344-8354.

5. Moore, K. T.; Fletcher, J. T.; Therien, M. J. Syntheses, NMR and EPR Spectroscopy, Electrochemical Properties, and Structural Studies of $[5,10,15,20$-Tetrakis(perfluoroalkyl)porphinato] iron(II) and -iron(III) Complexes. J. Am. Chem. Soc. 1999, 121, 5196-5209.

6. Tsuchiya, S.; Seno, M. Novel Synthetic Method of Phenol from Benzene Catalyzed by Perfluorinated Hemin. Chem. Lett. 1989, $18,263-266$.

7. Grancho, J. C. P.; Pereira, M. M.; Miguel, M. D. G.; Gonsalves, A. M. R.; Burrows, H. D. Synthesis, Spectra and Photophysics of Some Free Base Tetrafluoroalkyl and Tetrafluoroaryl Porphyrins with Potential Applications in Imaging. Photochem. Photobiol. 2002, 75, 249-256.

8. Chen, L.; Jin, L.-M.; Guo, C.-C.; Chen, Q.-Y. Fluoroalkylation of Porphyrins: Generation of 2- and 20-Perfluoroalkyl-5,10,15triarylporphyrin Radicals and their Intramolecular Cyclizations. Synlett 2005, 963-970.

9. Zeng, Z.; Liu, C.; Jin, L.-M.; Guo, C.-C.; Chen, Q.-Y. Unexpected Intramolecular Cyclization of 2-(Perfluoroalkyl)tetraarylporphyrin Radicals: Approaches for the Intramolecular Cyclization of 2-(Perfluoroalkyl)tetraarylporphyrin Radicals. Eur. J. Org. Chem. 2005, 306-316.

10. Van Berkel, G. J.; McLuckey, S. A.; Glish, G. L. Electrospray Ionization of Porphyrins Using a Quadrupole Ion Trap for Mass Analysis. Anal. Chem. 1991, 63, 1098-1109.

11. Van Berkel, G. J.; McLuckey, S. A.; Glish, G. L. Electrochemical Origin of Radical Cations Observed in Electrospray Ionization Mass Spectra. Anal. Chem. 1992, 56, 1586-1593.
12. Rosell-Melé, A.; Carter, J. F.; Maxwell, J. R. High-Performance Liquid Chromatography-Mass Spectrometry of Porphyrins by Using an Atmospheric Pressure Interface. J. Am. Soc. Mass. Spectrom. 1996, 7, 965-971.

13. Vandell, V. E.; Limbach, P. A. Electrospray Ionization Mass Spectrometry of Metalloporphyrins. J. Mass. Spectrom. 1998, 33, 212-220.

14. Quirke, J. M. E. In The Porphyrin Handbook; Kadish, K. M., Smith, K. M., Guilard, R., Eds.; Academic Press: San Diego, 2000; Vol. 7, pp 371-426.

15. McCarthy, J. R.; Melfi, P. J.; Capetta, S. H.; Brückner, C. Use of $\mathrm{Ag}(\mathrm{II})$ as a Removable Template in Porphyrin Chemistry: Diol Cleavage Products of [meso-Tetraphenyl-2,3-cis-diolchlorinato]silver(II). Tetrahedron 2003, 59, 9137-9146.

16. Izquerido, R. A.; Barros, C. M.; Santana-Marques, M. G.; Correia, éA. J. F.; Silva, A. M. G.; Tome, A. C.; Silva, A.; Neves, M. G. P. M. S.; Cavaleiro, J. A. S. Cycloreversion and Other Gas-Phase Reactions of Neutral and Cationic Pyrrolidine-Fused Chlorins and Isobacteriochlorins under Ion Bombardment and Electrospray. Rapid Commun. Mass. Spectrom. 2004, 18, 26012611.

17. Cole, R. B. Some Tenets Pertaining to Electrospray Ionization Mass Spectrometry. J. Mass. Spectrom. 2000, 35, 763-772.

18. Lau, K. S. F., Sadilek, M., Khalil, G. E., Gouterman, M. P., Brückner, C. Observation of Novel Porphyrinoid Structures During the ESI Mass Spectrometric Analysis of meso-Phenylporpholactone and meso-Pentafluorophenyl-Substituted Porphyrins, Porpholactones, and Corroles. (Manuscript submitted). 